\title{
A girl with extremely refractory Kawasaki disease: an instructive case with unusual course and outcome - CORRIGENDUM
}

Kossiva Lydia, Karanassios Evangelos, Papadopoulos George, Karavanaki Kyriaki

First published online: 28 May 2012

doi:10.1017/S1047951111001260, Published by Cambridge University Press, 21 September 2011.

The authors regret that in the originally published paper, all authors are mentioned by their first name and the initial of their surname. The correct writing of the authors names is as follows:

Kossiva L, Karanassios E, Papadopoulos G, Karavanaki K

The authors apologise for their error.

\section{Reference}

Lydia K, Evangelos K, George P, Kyriaki K. A girl with extremely refractory Kawasaki disease: an instructive case with unusual course and outcome. Published by Cambridge University Press 21 September 2011. 